\title{
Body water measurement in growth disorders: a comparison of bioelectrical impedance and skinfold thickness techniques with isotope dilution
}

\author{
J W Gregory, S A Greene, C M Scrimgeour, M J Rennie
}

\begin{abstract}
Total body water was estimated as part of the assessment of body composition in children with growth disorders, using the newly commercially available method of bioelectrical impedance. This was undertaken to compare the precision and accuracy of the results with those derived from skinfold thickness against measurement of stable isotopically labelled water $\left(\mathrm{H}_{2}{ }^{18} \mathrm{O}\right)$ dilution as a standard. The comparisons were carried out to see to what extent the impedance method could be applied with confidence to assessment of children with growth disorders. Total body water was derived from impedance (I) using an association with height $\left(\mathrm{Ht}^{2} / \mathrm{I}\right)$. Impedance and skinfold thickness estimates of total body water were equally precise when compared with values obtained from $\mathrm{H}_{2}{ }^{18} \mathrm{O}$ dilution (limits of agreement -1.9 to +1.3 and -1.7 to $+2.0 \mathrm{~kg}$ respectively). The mean intraobserver coefficient of variation for repeat measurements of impedance was $\mathbf{0 . 9 \%}$ compared with $\mathbf{4 \cdot 6} \%$ for skinfold thickness with an interobserver coefficient of variation for impedance of $\mathbf{2 \cdot 8 \%}$. Bioelectrical impedance estimation of body composition is likely to be of value in the growth clinic when expertise in measurement of skinfold thickness is limited or repeated measurements are to be undertaken by different observers.
\end{abstract}

Body composition measurement is useful in the diagnosis of pathology, assessment of disease progress and response to treatment. Techniques currently in use are mostly indirect, often expensive, difficult, and time consuming. Furthermore, the original reference data for body composition was based on the chemical analysis of the cadavers of six adults, several of whom died of illnesses likely to make their body composition unrepresentative. ${ }^{1}$ Values for body composition of children have often been derived by extrapolation from those values together with those obtained from the chemical analysis of a 4.5 year old boy and newborn infants. ${ }^{2}$

Densitometric analysis of body fat content by the underwater weighing technique is not widely applicable in the clinical context and is based on uncheckable assumptions concerning the density of fat and lean tissues. Skinfold thickness measurement is a standard method of body composition assessment in clinical paediatric practice. Regression equations derived from underwater weighing ${ }^{3}$ and deuterium oxide dilution ${ }^{4}$ methods for the calculation of body density and thus body fat ${ }^{5}$ from the sum of four skinfold thicknesses have been published for use in adolescents ${ }^{3}$ and prepubertal children. ${ }^{4}$ The method of skinfold thicknesses may, however, be unreliable because distribution of fat within the body may vary with sex, age, and race. ${ }^{1}$ There is considerable variability between measurements made by different observers on the same individual and the technique requires practice to reduce the error to the minimum possible with a single observer.

The present 'gold standard' for body water measurement from which body composition may be estimated depends on the dilution of isotopically labelled water tracer. This assumes that the tracer is uniformly distributed throughout the body water compartments and excreted like native water. Tritium is radioactive and thus ethically unacceptable for use in children but both deuterium $\left({ }^{2} \mathrm{H}\right)$ and ${ }^{18} \mathrm{O}$ are stable isotopes that may be used as tracers of water without radiation hazard. $\mathrm{H}_{2}{ }^{18} \mathrm{O}$ is expensive and in short supply but the $\mathrm{H}_{2}{ }^{18} \mathrm{O}$ dilution space is a more accurate measure of total body water, usually about $3 \%$ less than the ${ }^{2} \mathrm{H}_{2} \mathrm{O}$ space ${ }^{6}$ because of greater exchange of ${ }^{2} \mathrm{H}$ with nonaqueous components. However, isotopic analysis of ${ }^{18} \mathrm{O}$ requires expensive mass spectrometric facilities and expertise in their use.

The measurement of impedance is a technique for the indirect estimation of total body water and has recently been evaluated in several clinical situations. It is based on the association between the physical dimensions and electrical properties of a conductor. The impedance to the passage of a current through a conductor varies directly with the product of its volume resistivity and the length squared and inversely with its volume. Hoffer et al have confirmed that in the human body, assuming water to be the electrical conductor, total body water is related closely to height ${ }^{2} /$ impedance $\left(\mathrm{Ht}^{2} / \mathrm{I}\right){ }^{7}$ The technique has been validated in adults, ${ }^{8-10}$ but there is little information on its use in children. Given that the technique is quick, safe, and non-invasive, it should be of particular value in the assessment of body composition in children.

We have therefore undertaken a preliminary study in children with growth disorders to assess how well bioelectrical impedance predicts total body water determined by $\mathrm{H}_{2}{ }^{18} \mathrm{O}$ dilution in those circumstances. We have compared the results with those from measurements of skinfold thickness to identify the relative utility of each of the simple indirect methods.

Patients and methods

Thirty four children (28 boys, six girls) under- 
Table 1 Details of patients and measurements

\begin{tabular}{|c|c|c|}
\hline & Mean $(S D)$ & Range \\
\hline $\begin{array}{l}\text { Age (years) } \\
\text { Height (cm) } \\
\text { Height SDS } \\
\text { Weight (kg) }\end{array}$ & $\begin{aligned} 12 \cdot 0 & (2 \cdot 5) \\
132 \cdot 4 & (13 \cdot 6) \\
-2 \cdot 56 & (1 \cdot 08) \\
29 \cdot 9 & (8 \cdot 1)\end{aligned}$ & $\begin{array}{c}7 \cdot 4 \text { to } 15 \cdot 7 \\
106 \cdot 5 \text { to } 151 \cdot 7 \\
-4.60 \text { to } 1.06 \\
15 \cdot 7 \text { to } 49 \cdot 8\end{array}$ \\
\hline $\begin{array}{l}\text { Total body water } \\
\left(\mathrm{H}_{2}^{18} \mathrm{O} \text { dilution) }(\mathrm{kg})\right. \\
\text { Total skinfolds (mm) } \\
\text { Resistance (ohms) }\end{array}$ & $\begin{array}{c}17 \cdot 3(4 \cdot 3) \\
33 \cdot 5(16 \cdot 0) \\
608(71)\end{array}$ & $\begin{array}{c}9 \cdot 3 \text { to } 25 \cdot 1 \\
17 \cdot 0 \text { to } 78 \cdot 0 \\
489 \text { to } 742\end{array}$ \\
\hline
\end{tabular}

SDS $=$ growth measurement expressed as standard deviation score for chronological age. ${ }^{19}$

going investigation of growth disorders were assessed. Of these, 19 had constitutionally delayed puberty (height $<3$ rd centile, bone age delay $>1.5$ years), nine had growth hormone deficiency (growth hormone $<10 \mu \mathrm{g} / 1$ in response to a standard insulin stress test, ${ }^{11}$ and six had normal variant short stature (height $<3$ rd centile, growth hormone $>10 \mu \mathrm{g} / \mathrm{l}$ in response to a standard insulin stress test). Details of the subjects are shown in table 1 and these children are representative of the referral pattern to our clinic. Height was measured using a Holtain stadiometer and weight with a beam balance.

Total body water was measured from $\mathrm{H}_{2}{ }^{1 \gamma} \mathrm{O}$ dilution after giving $0.3 \mathrm{~g} \mathrm{H}_{2}{ }^{18} \mathrm{O} / \mathrm{kg}$ estimated total body water by mouth after an overnight fast $\left({ }^{18} \mathrm{O}\right.$ was 10.4 atom $\%$ from Isotec Inc). Urine specimens for analysis were taken before and five hours after the dose. Urine aliquots of $400 \mu \mathrm{l}$ were equilibrated with $5 \%$ carbon dioxide in $20 \mathrm{ml}$ Vacutainers (Becton Dickinson) for three days before analysis of the carbon dioxide for ${ }^{18: 16} \mathrm{O}$ ratio using a Finnigan MAT Delta $\mathrm{D}$ gas isotope ratio mass spectrometer fitted with an automated breath gas analysis system. ${ }^{12}$ Standard corrections for fractionation and dilution of the label by the added carbon dioxide were applied. ${ }^{13}$ Total body water was calculated by the method of Schoeller et al after standardising the enrichment of the given tracer by analysis of suitable dilutions with tap water. ${ }^{6}$

Bioelectrical impedance measurements were made using Holtain body composition analyser (Holtain Limited). The technique is simple to perform and highly acceptable to patients. Electrodes are applied for a few seconds to the dorsum of the right wrist and to the flexor surface of the right ankle through which a harmless $800 \mu \mathrm{A}, 50 \mathrm{khz}$ high frequency alternating current is passed allowing the impedance to be measured.

Skinfold measurements were made by a single observer (JWG) using a Holtain skinfold caliper from the triceps, biceps, subscapular, and suprailiac sites as described previously. ${ }^{3}$ Separate regression equations were used for converting the sum of the four skinfold thicknesses into body density for prepubertal ${ }^{4}$ and adolescent $^{3}$ children. Fat mass was calculated ${ }^{5}$ and for comparative purposes total body water was deduced (assuming that fat mass is anhydrous and fat free mass contains $730 \mathrm{~g}$ water/ $\mathrm{kg}$ weight ${ }^{14}$ ) using the equation, total body water= $0.73 \times$ (weight - fat mass).

Comparison of the values for total body water obtained from impedance and skinfold techniques with those obtained by isotope dilution were made using the method of Bland and Altman. ${ }^{15}$ This entails comparing the difference between the methods against the mean of the two methods, with results expressed as the bias (mean of the differences) together with its limits of agreement (mean (2 SD) difference) and the $95 \%$ confidence intervals for the lower and upper limits.

\section{Results}

Subject details and measurements by each technique are shown in table 1 . The association for $\mathrm{Ht}^{2} / \mathrm{I}$ and total body water derived from $\mathrm{H}_{2}{ }^{18} \mathrm{O}$ dilution produced the regression equation: total body water $=0.79+0.55 \quad\left(\mathrm{Ht}^{2} / \mathrm{I}\right)$ (figure). Statistical analysis of the variance involved in prediction of total body water by values derived from impedance and skinfold thickness measurements suggests both methods are of similar precision when compared with the $\mathrm{H}_{2}{ }^{18} \mathrm{O}$ dilution method (table 2). ${ }^{15}$

Repeated measurements of impedance by the same observer at the same time of day resulted in a mean coefficient of variation for the measurement of $0.9 \%$. When repeat measurements were made at different times throughout the day regardless of mealtimes or a full bladder, the coefficient of variation only increased to $2 \cdot 4 \%$. Repeat measurements on the same occasion by different observers resulted in a coefficient of

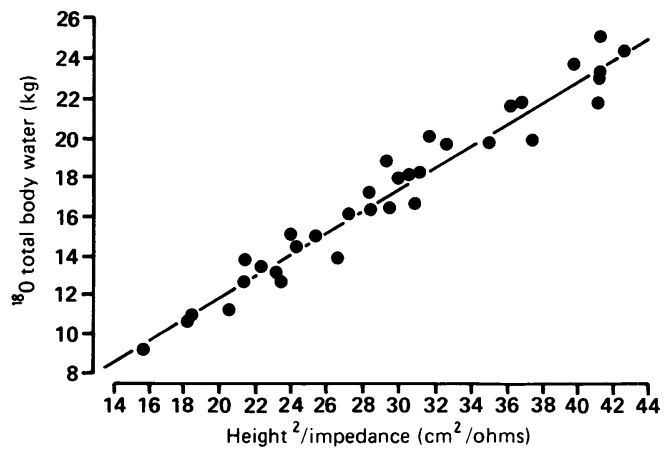

The association between height ${ }^{2} /$ impedance $\left(\mathrm{Ht}^{2} / \mathrm{I}\right)$ and total body water measured by $\mathrm{H}_{2}^{18} \mathrm{O}$ dilution. Total body water $=0.79+0.55\left(\mathrm{Ht}^{2} / \mathrm{I}\right)$.

Table 2 Total body water $(\mathrm{kg})$ derived from $\mathrm{H}_{2}{ }^{18} \mathrm{O}$ dilution compared with that from skinfold thickness and impedance $\left(H t^{2} / I\right)$

\begin{tabular}{|c|c|c|c|}
\hline & $\begin{array}{l}\text { Skinfold } \\
\text { thickness }\end{array}$ & $\begin{array}{l}\mathrm{Ht}^{2} / \mathrm{I} \\
\text { (this study) }\end{array}$ & $\begin{array}{l}t^{2} / I \\
(\text { Davies } \\
\left.\text { et } \text { al }^{\prime 8}\right)\end{array}$ \\
\hline $\begin{array}{l}\text { r } \\
\text { Bias } \\
\text { Limits of agreement } \\
95 \% \text { Confidence interval: }\end{array}$ & $\begin{array}{l}0.98 \\
-0.3 \\
-1.9 \text { to } 1.3\end{array}$ & $\begin{array}{l}0.98 \\
0.1 \\
-1 \cdot 7 \text { to } 2 \cdot 0\end{array}$ & $\begin{array}{l}0.98 \\
-0.1 \\
-2.0 \text { to } 1.9\end{array}$ \\
\hline $\begin{array}{l}\text { Lower limit } \\
\text { Upper limit }\end{array}$ & $\begin{array}{r}-2.4 \text { to }-1.4 \\
0.8 \text { to } 1.8\end{array}$ & $\begin{array}{r}-2 \cdot 3 \text { to }-1 \cdot 2 \\
1 \cdot 4 \text { to } 2 \cdot 5\end{array}$ & $\begin{array}{c}-2.6 \text { to }-1.4 \\
1.3 \text { to } 2.5\end{array}$ \\
\hline
\end{tabular}


variation of $2 \cdot 8 \%$. In contrast, the coefficient of variation for repeat skinfold measurements taken by a single experienced observer was $4 \cdot 6 \%$.

The application of skin electrodes in the use of the impedance technique was perceived as less threatening and thus better tolerated than the use of skinfold calipers in children under the age of 8 and in our experience may be used without difficulty in children as young as 3 years old (unpublished data).

\section{Discussion}

The principles of bioelectrical impedance were described nearly 30 years ago, ${ }^{16}{ }^{17}$ but only in the last five years have instruments suitable for clinical measurement become available. Our study confirms the results of Davies et al who derived total body water from impedance in 26 children and adolescents with a variety of disorders (inflammatory bowel disease, growth hormone deficiency, diabetes, and obesity). ${ }^{18}$ We found a mathematical association very similar to their findings (total body water $=-0.5+$ $\left.0.6 \times \mathrm{Ht}^{2} / \mathrm{I}\right)$. The study of Davies et al involved children with a variety of illnesses and it is reassuring that in our own study, focusing on children with growth disorders in whom fat content may be abnormal, that the above association holds. Together these results suggest that impedance may be reliably used for the assessment of body composition in paediatric practice, although clearly much larger studies are necessary to confirm the precision of the technique in girls and in disorders other than those affecting growth.

Our results (table 2) comparing both impedance and the established technique of skinfold thickness estimation with $\mathrm{H}_{2}{ }^{18} \mathrm{O}$ dilution show concordance of estimates of the bias and extent of agreement of the indirect methods in predicting total body water, although the confidence intervals for the limits of agreement are wide, reflecting the small size of our sample and the inherent imprecision of indirect measurements of total body water. The concordance holds even when estimates of total body water based only on published equations are compared. ${ }^{3418}$ This avoids the minimisation of prediction error that is introduced when our equation for deriving total body water from impedance is compared with total body water derived from isotope dilution, the former having previously been derived from the latter. Impedance and skinfold techniques, when used by a single experienced observer, are of comparable precision in the assessment of total body water, though the coefficient of variation for repeat measurements by the former method is considerably less.
In summary, bioelectrical impedance appears to be at least as accurate and precise a method for the measurement of total body water as the skinfold thickness technique performed by a single experienced observer. The impedance method is of advantage with younger children or when the clinician has limited expertise in skinfold measurement. It is also of value when different observers are undertaking serial measurements; this is because of the smaller variation in values obtained by one or more than one observer and so is the preferred choice when monitoring patients' response to treatment.

This work was supported by grants from the Biomedical Research Council of The Scottish Home and Health Department Novo-Nordisk A/S, and Organon Laboratories.

1 Garrow JS. Measurement of energy stores. Obesity and related diseases. Edinburgh: Churchill Livingstone, 1988:25-52. 2 Fomon SJ, Haschke F, Ziegler EE, Nelson SE. Body com position of reference children from birth to age 10 years. Am $\mathcal{F}$ Clin Nutr 1982;35:1169-75.

3 Durnin JVGA, Rahaman MM. The assessment of the amoun of fat in the human body from measurements of skinfold thickness. Br $\mathcal{F}$ Nutr 1967;21:681-9.

4 Brook CGD. Determination of body composition of children from skinfold measurements. Arch Dis Child 1971;46:1824.

5 Siri WE. Body composition from fluid spaces and density: analysis of methods. In: Brozek J, Henschel A, eds. Techniques for measuring body composition. Washington DC: Natioques for measuring body composition. Wash.

6 Schoeller DA, van Santen E, Peterson DW, et al. Total body water measurement in humans with ${ }^{18} \mathrm{O}$ and ${ }^{2} \mathrm{H}$ labeled water measurement in humans with

7 Hoffer EC, Meador CK, Simpson D. Correlation of wholebody impedance with total body water volume. $\mathcal{F}$ Appl Physiol 1969;27:531-4.

8 Lukaski HC, Johnson PE, Bolonchuk WW, Lykken GI. Assessment of fat-free mass using bioelectrical impedance measurements of the human body. Am $\mathcal{J}$ Clin Nutr 1985;41:810-7

9 Lukaski HC, Bolonchuk WW, Hall CB, Siders WA. Validation of tetrapolar bioelectrical impedance method to assess human body composition. F Appl Physiol 1986;60: 1327-32.

10 Segal KR, Gutin B, Presta E, Wang J, van Itallie TB. Estimation of human body composition by electrical impedance methods: a comparative study. $f$ Appl Physiol 1985;58: 1565-71.

11 Hughes IA. Handbook of endocrine tests in children. Bristol: Wright, 1986:133-4.

12 Scrimgeour CM, Rennie MJ. Automated measurement of the concentration and ${ }^{13} \mathrm{C}$ enrichment of carbon dioxide in breath and blood samples using the Finnigan MAT breath bas analysis system. Biomed Environ Mass Spectrom gas analysis syst.

13 Wong WW, Lee LS, Klein PD. Deuterium and oxygen-18 measurements on microliter samples of urine, plasma, saliva, and human milk. Am f Clin Nutr 1987;45:905-13.

14 Rathbun EN, Pace N. Studies on body composition. The body water and chemically combined nitrogen content in relation to fat content. F Biol Chem 1945;158:685-91.

15 Bland JM, Altman DG. Statistical methods for assessing agreement between two methods of clinical measurement. Lancet 1986; i:307-10.

16 Thomasset A. Bioelectric properties of tissue. Impedance measurement in clinical medicine. Significance of curves obtained. Lyon Medical 1962;94:107-18.

17 Thomasset A. Bioelectric properties of tissues. Estimation by measurement of impedance of extracellular ionic strength and intracellular ionic strength in the clinic. Lyon Medical 1963;209:1325-52.

18 Davies PSW, Preece MA, Hicks CJ, Halliday D. The prediction of total body water using bioelectrical impedance in children and adolescents. Ann Hum Biol 1988;15:237-40.

19 Tanner JM, Whitehouse RH, Takaishi M. Standards from birth to maturity for height, weight, height velocity and weight velocity: British 